\title{
RBEP
}

\section{O ovo ou a galinha: a crise da profissão docente e a aparente falta de perspectiva para a educação brasileira*}

Júlio Emílio Diniz-Pereira

\section{Resumo}

O ovo ou a galinha é uma referência a um dilema de causalidade que surge da conhecida expressão "O que veio antes, o ovo ou a galinha?" Temos a sensação de que estamos diante de um dilema semelhante quando discutimos a crise da profissão docente em nosso País: seria a crise das licenciaturas, em função da sua baixa procura e o número supostamente insuficiente de diplomados, que levaria a uma crise do magistério ou esta que explicaria os problemas enfrentados pelos cursos de formação docente? Neste artigo, apresentarei argumentos demonstrando que a crise da profissão docente apresenta múltiplos fatores e que existem formas de se sair desse suposto dilema.

Palavras-chave: formação de professores; licenciaturas; crise.

\section{Abstract \\ The egg or the hen: the crisis of the teaching profession and the lack of perspective for Brazilian education}

The egg or the hen is a reference to the causality dilemma that emerges from the expression: "what comes first, the egg or the hen?"
* Este texto subsidiou a palestra de mesmo título proferida pelo autor durante o X Congresso Estadual Paulista sobre Formação de Educadores, em Águas de Lindoia, São Paulo, no dia 31 de agosto de 2009. 
One comes across a similar dilemma concerning the crisis of the teaching profession in the country: would it be a consequence of the crisis in teacher education courses, considering the lack of demand for these courses together with the insufficient number of professionals holding a diploma, or would this be the real cause of the problems in the teacher education courses? This article presents different points of view in order to highlight the multiple factors related to the teaching profession crisis as well as some ways to avoid this dilemma.

Keywords: teacher training; teacher education degrees; crisis.

\section{O significado da palavra crise}

"Crise" se origina da palavra grega krísis e significa fase grave, complicada, difícil, um momento de tensão ou de impasse na vida de uma pessoa, de um grupo social, na evolução de determinadas situações. É também definida como manifestação violenta e repentina de ruptura de equilíbrio ou um estado de dúvidas e incertezas, um momento perigoso ou decisivo, de muita tensão e conflito.

As dimensões centrais que caracterizam a crise são: a alteração do estado de legitimidade social por meio da violação de valores, normas e códigos socialmente estabelecidos e, consequentemente, a ruptura de uma situação de equilíbrio ou estabilidade, a imprevisibilidade dessa situação e a urgência de julgamentos, decisões e respostas por parte dos envolvidos.

Tais dimensões podem ser identificadas por meio da atual crise econômica mundial, por exemplo. A ganância de imobiliárias e instituições financeiras norte-americanas, que violaram normas e códigos estabelecidos, e a falta de regulação por parte do Estado para fazer valer o cumprimento desses princípios levaram à instabilidade econômica de todo o planeta. Apesar de alguns sinais de recuperação, ainda não se conhecem as consequências dessa crise para a economia global. Dos líderes mundiais e cidadãos comuns, são exigidas respostas rápidas diante dessa situação.

Outros exemplos conhecidos de "crise" são a da adolescência, em função das mudanças bruscas que acontecem em nossos corpos nessa fase da vida, as de relacionamento, que algumas vezes levam à ruptura, à separação e ao divórcio, e a financeira, que tanto no âmbito familiar quanto no institucional ou governamental gera enormes tensões, conflitos e incertezas. Ainda podíamos citar a crise ambiental, a crise política, a crise de identidade, a crise existencial, a crise de caráter... Na epistemologia, a não menos conhecida "crise de paradigmas", e, do ponto de vista político-ideológico, a eterna crise da esquerda. 
Resumindo, "crise" refere-se a qualquer momento ou situação afetada por uma perda de estabilidade, de equilíbrio, ou que preceda ou provoque uma anormalidade grave no funcionamento da sociedade, das instituições, da economia e na vida das pessoas. Em geral, as situações de crise exigem respostas adequadas e rápidas.

No Brasil, já há algum tempo, observam-se sinais e evidências de uma profunda crise da profissão docente. Porém, infelizmente, as respostas dos governantes brasileiros para tal situação têm sido, via de regra, insuficientes, equivocadas e ineficazes.

\section{Alguns sinais de crise da profissão docente no Brasil}

Apesar da definição anterior de "crise" como "manifestação violenta e repentina de ruptura de equilíbrio", podemos afirmar que, no caso da profissão docente, particularmente quanto aos cursos de formação de professores, já existiam nas décadas de 1980 e 1990 nítidos sinais de uma profunda crise do magistério no Brasil.

Por meio da análise da literatura educacional, percebe-se que a vinculação dos problemas da formação do professor às dificuldades gerais enfrentadas pela educação brasileira foi bastante defendida a partir do final da década de 1970.

Denunciou-se, por exemplo, que a expansão do sistema público de ensino - e, por via de consequência, a democratização do acesso à educação básica - não foi seguida por um correspondente investimento das verbas públicas destinadas à educação. A demanda de um número cada vez maior de professores para uma população escolar crescente foi, de certa forma, atendida pela expansão do ensino superior, principalmente mediante um alargamento do ensino privado ${ }^{1}$ e a criação indiscriminada de cursos de licenciatura. ${ }^{2}$

A denúncia da crise educacional brasileira e a concomitante defesa de melhores condições de trabalho e salários dignos para o magistério apareceram com alguma frequência nos textos sobre formação de professores da década de 1980 (Balzan, 1985; Balzan, Paoli, 1988). Dessa maneira, a discussão sobre a formação de professores ampliou-se quando o contexto da escola, a falta de condições materiais do trabalho docente e a condição de assalariado do professor passaram a ser considerados temas importantes no debate.

Chamou-se a atenção, então, para outras dimensões, normalmente não explicitadas, que determinavam o fracasso do trabalho docente na escola. Criticou-se, por exemplo, a ênfase dada à formação de professores como modo de garantir a qualidade do ensino praticado na escola sem ao menos mencionar os processos "deformadores" e "desqualificadores" aos quais esses profissionais estavam submetidos. Ou seja, questionouse o fato de o debate centrar-se na formação do professor e não na sua deformação a partir do momento em que ele se insere no mercado de trabalho. Introduziu-se, dessa maneira, uma questão fundamental: "Quem de-forma o profissional do ensino?" (Arroyo, 1985).

\footnotetext{
1 É inegável que houve uma inversão no sistema de ensino superior brasileiro quanto ao crescimento dos setores público e privado. Fruto de uma política governamental que privilegiou o sistema privado em detrimento do público, o crescimento do ensino superior brasileiro tornou-se dependente da iniciativa privada. Em relação à oferta de vagas no ensino superior, por exemplo, os números demonstram uma inversão no atendimento em relação à década de 70 , quando $1 / 3$ do sistema era privado e $2 / 3$ eram públicos (Marques, DinizPereira, 2002)

${ }^{2}$ O governo federal vem respondendo ao problema da falta de professores certificados/qualificados na educação básica com ações em diferentes frentes, pouco articuladas e mais preocupadas em mudar as estastísticas educacionais do que propriamente em enfrentar a questão de maneira qualitativa. Esses programas têm como base o uso de novas tecnologias voltadas para o ensino a distância (Marques, Diniz-Pereira, 2002).
} 
As condições do trabalho docente e a situação da carreira de magistério passaram a ser, então, bastante enfocadas no debate sobre a formação de professores. O aviltamento salarial e a participação cada vez menor na execução do seu próprio trabalho revelaram a existência de um crescente processo de proletarização do magistério brasileiro (Hypolito, 1991).

O processo de desvalorização e descaracterização do magistério, evidenciado pela progressiva perda salarial por parte dos professores e pela precária situação do seu trabalho na escola, determinou, a partir do final da década de 1970 e início dos anos 1980, o surgimento das primeiras greves de professores das escolas públicas e privadas, desencadeando um movimento de luta por melhores salários e melhores condições do trabalho docente.

Alguns autores (Kreütz, 1986; Haguette, 1991) levantaram a seguinte questão a respeito da identidade do trabalho docente: trata-se de uma vocação, uma profissão ou um bico? Aos dois primeiros marcos identitários já presentes no debate, "vocação" ou "profissão", somou-se um terceiro, o "bico", como consequência do total descaso com a carreira do professor no País.

Surgiram no meio acadêmico, especialmente a partir da segunda metade da década de 1980, várias denúncias sobre o descaso com que as questões relativas ao ensino eram tratadas nas universidades brasileiras, principalmente se comparado ao tratamento dispensado à pesquisa. A questão do ensino e da pesquisa nas universidades brasileiras apresentouse como uma "relação mal resolvida" (Balzan, 1994). A separação explícita entre essas duas atividades no seio da universidade e a valorização da pesquisa em detrimento do ensino (de graduação) no meio acadêmico traziam prejuízos enormes à formação profissional e, particularmente, à formação de professores.

A situação das licenciaturas foi considerada, então, insustentável. Existia, em relação aos cursos de formação de professores, um sentimento generalizado de que as coisas ali não mudavam e de que os problemas discutidos na época eram praticamente os mesmos desde a sua criação (Lüdke, 1994).

A separação entre "teoria" e "prática" foi o problema que mais fortemente emergiu da discussão sobre a formação de professores naquele período. A falta de articulação entre "disciplinas de conteúdo" e "disciplinas pedagógicas" foi considerada um dilema que, somado a outros dois, a dicotomia existente entre bacharelado e licenciatura e a desarticulação entre formação acadêmica e realidade prática, contribuiu para o surgimento de críticas sobre a fragmentação dos cursos de formação de professores. Essas são questões recorrentes nesse debate e que, ainda hoje, não saíram de pauta.

Todas essas questões enquadraram-se entre as convergências e as tensões do debate sobre a formação de professores no Brasil (Candau, 1987) e, infelizmente, continuam sendo problemas cada vez mais presentes nas discussões.

As mudanças ocorridas no cenário internacional a partir do final dos anos 1980 repercutiram no pensamento educacional e mais especificamente na produção acadêmica sobre a formação de professores. A 
partir do final da década de 1980, presenciamos uma intensa mudança no cenário político mundial: a proclamação do "fim da história", marcado pelo triunfo da ideologia capitalista e neoliberal.

No contexto econômico, a inovação tecnológica possibilitou a superação dos velhos paradigmas "taylorista" e "fordista", gerando uma nova lógica industrial. A adoção de um novo "paradigma tecnológico" passou a ser um importante projeto político. Apesar de todo esse avanço, as questões sobre injustiça e desigualdade social estavam ainda longe de desaparecer.

No meio acadêmico, anunciou-se o fim da modernidade e a entrada no período da pós-modernidade: iniciava-se a chamada "era das incertezas". Iniciamos os anos de 1990 convivendo com uma "suposta crise" de paradigmas nas Ciências Sociais, consequência da suposta perda de validade dos referenciais teóricos habituais.

O pensamento educacional, por sua vez, não ficou isento desse contexto de "suposta crise". A literatura na área da educação, bastante influenciada pela concepção marxista no início dos anos de 1980, cedeu lugar, na década de 1990, a estudos voltados para a compreensão dos aspectos microssociais da escola, destacando e focalizando sob novos prismas os papéis dos agentes-sujeitos (Santos, 1995), em especial, os professores: suas vozes, suas vidas e suas identidades.

Resumindo, o debate sobre a formação de professores apresenta, ao longo dos anos, elementos de conservação e de mudança. A recorrência de alguns temas nesse debate nos dá a impressão de estarmos discutindo os mesmos problemas durante anos e mesmo décadas, sem, no entanto, conseguir solucioná-los; essa sensação parece ser ainda mais forte no debate específico sobre a problemática das licenciaturas. Ao mesmo tempo, é possível perceber o surgimento de novos temas, novas questões, novas maneiras de pensar a formação docente que parecem apontar para "novos rumos", tanto para a formação de professores em geral como, especificamente, para os cursos de licenciatura.

Porém, é preciso enfatizar que as mudanças na maneira de pensar a formação de professores não garantem mudanças, alterações e inovações imediatas nos cursos de formação docente, especificamente nas licenciaturas. A efetivação de mudanças nesse âmbito parece ser mais lenta e seguir um caminho mais complexo.

\section{Evidências da crise da profissão docente no Brasil}

Por meio de uma pesquisa realizada em uma universidade federal do sudeste do Brasil e concluída em 1996, constatamos que nove dos dez cursos considerados de "menor prestígio" na universidade ofereciam a modalidade licenciatura e eram responsáveis pela formação de professores (Diniz-Pereira, 1996, 2000). ${ }^{3}$ Notou-se também que nenhum curso com opção para a licenciatura estava listado entre aqueles de "maior prestígio" (Quadro 1).

Apesar de um número relativamente grande de matrículas (em torno de $20 \%$ ), o número de graduados em licenciatura, ou seja, daqueles que

\footnotetext{
${ }^{3}$ Foram considerados de "menor prestígio" os cursos que permaneceram entre aqueles com menor relação candidato/vaga nos vestibulares, ou seja, não eram os preferencialmente escolhidos pelos candidatos a uma vaga na instituição.
} 
efetivamente se formaram "professor", foi pequeno (Tabela 1). Com base nessa pesquisa e outras similares (Pagotto, 1988; Tancredi, 1995), pode-se dizer que, naquela época, a contribuição das universidades públicas na formação de docentes para o ensino médio e fundamental não era bastante expressiva.

\section{Quadro 1 - Cursos de "maior" e de "menor prestígio" em uma universidade} pública da Região Sudeste - 1995

\begin{tabular}{|l|l|}
\multicolumn{1}{|c|}{ Cursos de "maior prestígio" } & \multicolumn{1}{c}{ Cursos de "menor prestígio" } \\
\hline Administração (diurno) & Biblioteconomia \\
\hline Arquitetura & Ciências Sociais \\
\hline Ciência da Computação & Filosofia \\
\hline Ciências Econômicas & Geografia (diurno) \\
\hline Comunicação Social & Geografia (noturno) \\
\hline Direito & História (diurno) \\
\hline Engenharia Civil & História (noturno) \\
\hline Engenharia Mecânica & Matemática \\
\hline Engenharia Química & Pedagogia (diurno) \\
\hline Medicina & Pedagogia (noturno) \\
\hline
\end{tabular}

Fonte: Elaboração própria a partir de dados fornecidos pela Comissão Permanente do Vestibular (Copeve) da universidade pesquisada

Nota: Foram considerados de "menor prestígio" os cursos com menor relação candidato/vaga nos vestibulares, ou seja, não eram os preferencialmente escolhidos pelos candidatos a uma vaga na instituição.

Tabela 1 - Número de alunos graduados nos cursos com modalidade licenciatura em uma universidade pública da Região Sudeste - $1^{\circ}$ semestre 1990-1º semestre 1995

\begin{tabular}{|c|c|c|c|c|c|c|c|c|c|c|c|c|}
\hline Cursos & $90 / 1$ & $90 / 2$ & $91 / 1$ & $91 / 2$ & $92 / 1$ & 92/2 & $93 / 1$ & 93/2 & $94 / 1$ & $94 / 2$ & $95 / 1$ & Média \\
\hline Belas Artes & 35 & 24 & 29 & 32 & 39 & 32 & 28 & 36 & 52 & 40 & 23 & 33,64 \\
\hline $\begin{array}{l}\text { Ciências Biológicas } \\
\text { (diurno) }\end{array}$ & 45 & 42 & 31 & 47 & 46 & 46 & 36 & 34 & 36 & 58 & 42 & 42,09 \\
\hline Ciências Sociais & 27 & 26 & 20 & 22 & 26 & 29 & 11 & 24 & 22 & 19 & 15 & 21,91 \\
\hline Educação Física & 28 & 37 & 37 & 39 & 34 & 45 & 38 & 36 & 27 & 45 & 47 & 37,54 \\
\hline Enfermagem & 25 & 17 & 39 & 23 & 30 & 36 & 30 & 38 & 54 & 37 & 38 & 33,36 \\
\hline Filosofia & 6 & 13 & 13 & 19 & 15 & 9 & 8 & 15 & 17 & 18 & 2 & 12,27 \\
\hline Física (diurno) & 4 & 11 & 5 & 5 & 14 & 11 & 5 & 5 & 7 & 20 & 6 & 8,45 \\
\hline Geografia (diurno) & 8 & 28 & 3 & 14 & 4 & 19 & 10 & 19 & 16 & 30 & 13 & 14,91 \\
\hline História (diurno) & 15 & 64 & 19 & 41 & 18 & 35 & 20 & 30 & 18 & 24 & 33 & 28,82 \\
\hline Letras & 82 & 97 & 86 & 88 & 106 & 108 & 95 & 120 & 95 & 99 & 90 & 96,91 \\
\hline Matemática (diurno) & 8 & 5 & 7 & 28 & 9 & 8 & 9 & 15 & 24 & 14 & 20 & 13,36 \\
\hline Música & 5 & 8 & 5 & 4 & 7 & 8 & 8 & 21 & 9 & 13 & 5 & 8,45 \\
\hline Pedagogia (diurno) & 72 & 50 & 81 & 11 & 76 & 11 & 76 & 4 & 67 & 7 & 73 & 48,00 \\
\hline Pedagogia (noturno) & - & - & - & 11 & 57 & 9 & 69 & 1 & 72 & 0 & 82 & 37,62 \\
\hline Psicologia & 52 & 127 & 94 & 97 & 113 & 128 & 137 & 128 & 120 & 76 & 78 & 104,54 \\
\hline Química (diurno) & 9 & 16 & 5 & 4 & 6 & 5 & 2 & 5 & 6 & 12 & 3 & 6,64 \\
\hline
\end{tabular}

Fonte: Elaboração própria a partir de dados coletados no Departamento de Registro e Cadastro Acadêmico (DRCA) da universidade pesquisada. 
As taxas médias de evasão nos cursos com modalidade licenciatura eram altíssimas, constituindo-se nas maiores da universidade (Tabela 2). Os percentuais mais elevados foram encontrados nos cursos de Química (78\%), Física (72\%), Filosofia, Matemática e Geografia (69\% cada). Esses índices estavam bem acima daqueles apresentados por outros cursos da universidade, como Medicina, Odontologia (3\% cada) e Arquitetura (14\%).

Em relação ao concurso vestibular, concluiu-se que existia entre os aprovados nos cursos "mais disputados" da universidade um claro predomínio de egressos da rede particular de ensino, que frequentaram cursos diurnos e não fizeram "cursinhos" ou os frequentaram por no máximo um semestre, dos que não trabalhavam e dos que tinham pais com escolaridade de ensino médio ou superior.

\section{Tabela 2 - Taxa média de diplomação, retenção e evasão nos cursos com modalidade licenciatura em uma universidade pública da Região Sudeste - 1995}

\begin{tabular}{|c|c|c|c|}
\hline Cursos & $\begin{array}{c}\text { Diplomação } \\
\text { (\%) }\end{array}$ & $\begin{array}{c}\text { Retenção } \\
(\%)\end{array}$ & $\begin{array}{c}\text { Evasão } \\
(\%)\end{array}$ \\
\hline Arquitetura & 86,00 & 1,00 & 14,00 \\
\hline Belas Artes & 63,00 & 1,00 & 37,00 \\
\hline Ciências Biológicas (diurno) & 59,00 & 2,00 & 38,00 \\
\hline Ciências Sociais & 46,00 & 2,00 & 52,00 \\
\hline Educação Física & 69,00 & 1,00 & 30,00 \\
\hline Enfermagem & 52,00 & 0,00 & 48,00 \\
\hline Estatística & 31,00 & 0,00 & 69,00 \\
\hline Filosofia & 31,00 & 0,01 & 69,00 \\
\hline Física (diurno) & 26,00 & 2,00 & 72,00 \\
\hline Geografia (diurno) & 30,00 & 2,00 & 69,00 \\
\hline História (diurno) & 53,00 & 0,00 & 47,00 \\
\hline Letras & 49,00 & 1,00 & 51,00 \\
\hline Matemática (diurno) & 29,00 & 1,00 & 69,00 \\
\hline Medicina & 97,00 & 0,00 & 3,00 \\
\hline Música & 47,00 & 9,00 & 44,00 \\
\hline Odontologia & 97,00 & 0,00 & 3,00 \\
\hline Pedagogia (diurno) & 65,00 & 0,00 & 35,00 \\
\hline Pedagogia (noturno) & 61,00 & 0,00 & 39,00 \\
\hline Psicologia & 78,00 & 0,00 & 22,00 \\
\hline Química (diurno) & 19,00 & 2,00 & 78,00 \\
\hline
\end{tabular}

Fonte: Elaboração própria a partir de dados fornecidos pela Pró-Reitoria de Graduação da universidade pesquisada.

Os dados mostraram também que havia heterogeneidade na composição sociocultural dos aprovados nos cursos com opção para a licenciatura da universidade. Existia nas licenciaturas um grupo formado 
pelos cursos de Ciências Biológicas (diurno), Ciências Sociais, Educação Física e História (diurno), cujas características mais se aproximavam daquelas observadas nos cursos "mais disputados" da universidade. Por outro lado, em grande parte dos cursos de licenciatura ingressaram muitos estudantes provenientes da rede pública de ensino, que frequentaram cursos noturnos, não fizeram "cursinhos" e tinham pais com escolaridade inferior ao ensino médio completo.

Pela análise, observou-se que os cursos de Comunicação Social, Direito e Medicina, entre os "mais disputados", os de Física diurno e Geologia, entre os "menos disputados", e os de Ciências Biológicas diurno, Educação Física, Ciências Sociais e História diurno, entre as licenciaturas, pareciam constituir vias de acesso à universidade para as frações de classe que possuíam maior capital econômico e cultural.

A menor posse de capital econômico e de relativo maior capital cultural caracterizaram frações de classe a que se vinculavam os aprovados para os cursos de Belas Artes e Música, entre os "menos disputados".

Com candidatos aprovados egressos de frações de classe com menos capital econômico e menos capital cultural apareceram os cursos de Fisioterapia, entre os mais disputados, e de Química diurno, entre os menos disputados; entre aqueles com opção para a licenciatura, destacaram-se os cursos noturnos em geral e os de Letras, Geografia diurno e Matemática diurno.

Os aprovados nos cursos de licenciatura apresentaram uma trajetória escolar bem menos privilegiada do que aquela mostrada para os cursos mais disputados da universidade. Em geral, os alunos das licenciaturas demoraram mais tempo para entrar no ensino superior - três anos ou mais após ter concluído o ensino médio. Os candidatos egressos da rede pública de ensino e das escolas técnica e noturna encontraram menor resistência para serem aprovados nos cursos que oferecem a licenciatura. Aqueles que não frequentaram o "cursinho" apareceram em grande número tanto nos cursos de "maior prestígio" quanto nas licenciaturas, provavelmente por motivos diferentes: no primeiro caso, os alunos não precisam desse "reforço" para enfrentar o vestibular, por serem dotados de capital cultural e por terem frequentado os melhores colégios, ou seja, por apresentarem um capital escolar diferenciado; no segundo, apesar dos alunos necessitarem desse tipo de "auxílio" para corrigirem eventuais falhas e lacunas do ensino médio, muitos não têm condições de pagá-lo. Essas diferenças podem ser explicadas em função da origem sociocultural desses alunos.

Considerando-se a renda total mensal familiar (Tabela 3), observou-se que a maioria das famílias dos aprovados nos cursos mais disputados da universidade ganhava de 11 a 60 salários mínimos por mês. Nos cursos de Comunicação Social (63,34\%) e Ciência da Computação (57,14\%), a renda mensal do grupo familiar da maioria dos candidatos bem sucedidos variava de 16 a 60 salários mínimos. Em Direito (57,66\%) e em Medicina (53,44\%), a maior parte recebia de 11 a 40 salários mínimos mensais. Na Fisioterapia, 57,50\% dos aprovados tinham um rendimento mensal 
que variava de 6 a 15 salários mínimos. Notou-se que o curso de Direito apresentava o maior percentual de famílias que recebiam mais de 60 salários mínimos mensais (11,33\%). Pode-se dizer, então, que os aprovados nesses cursos se caracterizam, em geral, pela posse relativamente maior de capital econômico.

Tabela 3 - Renda mensal do grupo familiar dos aprovados no vestibular em uma universidade pública da Região Sudeste - 1995

\begin{tabular}{|c|c|c|c|c|c|c|c|c|c|}
\hline Cursos & 1 & 2 & 3 & 4 & 5 & 6 & 7 & 8 & $\mathrm{~B} / \mathrm{N}$ \\
\hline Belas Artes** & 0,00 & 25,00 & 25,00 & 11,67 & 13,33 & 16,67 & 5,00 & 3,33 & 0,00 \\
\hline Ciência da Computação* & 4,29 & 7,14 & 20,00 & 11,43 & 18,57 & 25,71 & 12,86 & 0,00 & 0,00 \\
\hline $\begin{array}{l}\text { Ciências Biológicas } \\
\text { (diurno - Bach./Lic.) }\end{array}$ & 1,25 & 16,25 & 23,75 & 18,75 & 17,50 & 11,25 & 8,75 & 2,50 & 0,00 \\
\hline Ciências Biológicas (noturno - Lic.) & 7,50 & 25,00 & 37,50 & 10,00 & 7,50 & 2,50 & 5,00 & 2,50 & 2,50 \\
\hline Ciências Sociais & 6,15 & 20,00 & 15,38 & 23,08 & 9,23 & 13,85 & 7,69 & 3,08 & 1,54 \\
\hline Comunicação Social* & 1,67 & 6,67 & 8,33 & 15,00 & 20,00 & 26,67 & 16,67 & 5,00 & 0,00 \\
\hline Direito* & 0,33 & 0,33 & 14,33 & 13,33 & 16,00 & 28,33 & 12,67 & 11,33 & 0,33 \\
\hline Educação Física & 1,00 & 14,00 & 25,00 & 23,00 & 17,00 & 17,00 & 1,00 & 1,00 & 1,00 \\
\hline Enfermagem & 5,00 & 31,25 & 31,25 & 15,00 & 10,00 & 5,00 & 0,00 & 1,25 & 1,25 \\
\hline Filosofia & 7,50 & 7,50 & 25,00 & 22,50 & 12,50 & 12,50 & 0,00 & 7,50 & 5,00 \\
\hline Física (diurno - Bach.) ${ }^{* *}$ & 10,00 & 13,33 & 23,33 & 10,00 & 20,00 & 10,00 & 3,33 & 10,00 & 0,00 \\
\hline Física (noturno - Lic.) & 16,67 & 26,67 & 30,00 & 6,67 & 6,67 & 6,67 & 3,33 & 3,33 & 0,00 \\
\hline Fisioterapia* & 0,00 & 7,50 & 32,50 & 25,00 & 12,50 & 15,00 & 7,50 & 0,00 & 0,00 \\
\hline Geografia (diurno) & 2,50 & 40,00 & 27,50 & & 10,00 & 5,00 & 2,50 & 2,50 & 0,00 \\
\hline Geografia (noturno) & 3,33 & 23,33 & 36,67 & 16,67 & 6,67 & 10,00 & 0,00 & 3,33 & 0,00 \\
\hline Geologia** & 0,00 & 20,00 & 16,67 & 10,00 & 6,67 & 30,00 & 13,33 & 0,00 & 3,33 \\
\hline História (diurno) & 0,00 & 17,50 & 25,00 & 20,00 & 17,50 & 12,50 & 5,00 & 0,00 & 2,50 \\
\hline História (noturno) & 2,50 & 20,00 & 32,50 & 15,00 & 10,00 & 15,00 & 5,00 & 0,00 & 0,00 \\
\hline Letras & 4,17 & 22,92 & 28,75 & 16,67 & 12,50 & 8,33 & 2,50 & 2,08 & 2,08 \\
\hline Matemática (diurno - Licenciatura) & 3,33 & 33,33 & 23,33 & 16,67 & 13,33 & 3,33 & 3,33 & 0,00 & 3,33 \\
\hline Matemática (diurno - Bacharelado) & 5,00 & 10,00 & 25,00 & 20,00 & 30,00 & 0,00 & 0,00 & 5,00 & 5,00 \\
\hline Matemática (noturno) & 3,33 & 13,33 & 40,00 & 10,00 & 13,33 & 6,67 & 6,67 & 0,00 & 6,67 \\
\hline Medicina* & 0,94 & 4,38 & 20,63 & 14,38 & 17,50 & 21,56 & 10,94 & 8,75 & 0,94 \\
\hline Música** & 5,41 & 16,22 & 13,51 & 29,73 & 8,11 & 16,22 & 5,41 & 2,70 & 2,70 \\
\hline Pedagogia (diurno) & 6,67 & 26,67 & 23,33 & 16,67 & 11,67 & 8,33 & 1,67 & 5,00 & 0,00 \\
\hline Pedagogia (noturno) & 11,67 & 28,33 & 36,67 & 15,00 & 6,67 & 0,00 & 0,00 & 0,00 & 1,67 \\
\hline Psicologia & 4,17 & 18,33 & 14,17 & 17,50 & 15,00 & 20,83 & 7,50 & 1,67 & 0.83 \\
\hline Química (diurno)*** & 10,00 & 25,00 & 25,00 & 20,00 & 0,00 & 17,50 & 2,50 & 0,00 & 0,00 \\
\hline Química (noturno) & 3,33 & 20,00 & 50,00 & 16,67 & 10,00 & 0,00 & 0,00 & 0,00 & 0,00 \\
\hline
\end{tabular}

Fonte: Elaboração própria a partir de dados fornecidos pela Comissão Permanente do Vestibular (Copeve) da universidade pesquisada.

* Cursos com maior relação candidato/vaga no Vestibular/95.

** Cursos com menor relação candidato/vaga no Vestibular/95

Cabeçalho: 1 - Até 2 salários mínimos (SM); 2 - De 3 a 5 SM; 3 - De 6 a 10 SM; 4 - De 11 a 15 SM; 5 - De 16 a 20 SM; 6 - De 20 a 40 SM;

7 - De 40 a 60 SM; 8 - Acima de 60 SM; B/N - brancos e nulos. 
Na maioria dos cursos com menor relação candidato/vaga na universidade predominaram grupos familiares dos aprovados com rendimento mensal de 3 a 15 salários mínimos; é o caso de Química diurno (70,00\%), Belas Artes (61,67\%) e Música (59,46\%). No curso de Física diurno, a maior parte das famílias dos aprovados ganhava de 6 a 20 salários mínimos mensais. Sessenta por cento das famílias dos candidatos com bom desempenho em Geologia receberam de 11 a 60 salários mínimos mensais, e a metade delas $(30,00 \%)$ tinha uma remuneração mensal variando de 20 a 40 salários mínimos.

Em grande parte dos cursos com opção para a licenciatura, a maioria dos grupos familiares dos aprovados tinha uma renda mensal variando de 3 a 10 salários mínimos. Isso foi o que aconteceu nos seguintes cursos: Química noturno (70,00\%), Geografia diurno (67,50\%), Pedagogia noturno (65,00\%), Ciências Biológicas (62,50\%), Geografia (60,00\%), Física (56,67\%), História (52,50\%) e Letras (51,67\%). Em um outro grupo formado pelos cursos de Educação Física (65,00\%), Matemática noturno (63,33\%), Ciências Biológicas diurno (60,00\%), Filosofia (60,00\%) e Matemática diurno $(53,33 \%)$ predominaram as famílias de aprovados com remuneração mensal de 6 a 20 salários mínimos. Nos cursos de Pedagogia diurno (66,67\%) e Ciências Sociais (58,46\%), o rendimento mensal da maior parte das famílias dos candidatos que ingressaram na universidade variava de 3 a 15 salários mínimos.

Pelo exposto, pode-se concluir que as condições socioeconômicoculturais mais favoráveis (melhor renda, maior escolaridade e ocupações de maior prestígio) constituíram importante fator de aprovação nos cursos mais disputados da universidade. A origem sociocultural da maioria dos aprovados nos cursos com modalidade licenciatura era bem menos privilegiada que a dos alunos que optaram pelos cursos mais concorridos dessa instituição.

\section{A crise atual da profissão docente no Brasil}

O governo brasileiro acaba de anunciar que 330 mil pessoas atuam nas escolas da educação básica sem a habilitação mínima exigida por lei - isso depois de sermos oficialmente informados de que há um déficit de, aproximadamente, 250 mil professores de Matemática, Física, Química e Biologia no País.

Porém esses números parecem imprecisos, pouco confiáveis, e podem ser ainda maiores, uma vez que, em 1996, de acordo com as estatísticas oficiais, o déficit total de professores na educação básica brasileira era de um milhão e 200 mil docentes (Evangelista, 2000). E o próprio governo, por meio do Censo Escolar Inep/MEC, de 1998, anunciou que existiam aproximadamente 830 mil professores sem formação de nível superior atuando na educação básica brasileira.

De acordo com os dados coletados pelo Censo do Ensino Superior, em 2000, existiam no País 2.095 cursos de formação de professores de 
disciplinas específicas - Geografia, Biologia, Química, Física, Matemática, Línguas, História, entre outros - e 837 de Pedagogia.

Nesse período, foram recebidos cerca de cinco mil pedidos para abertura de novos cursos de formação docente, sendo que somente 647 receberam autorização, criando-se assim 59 mil novas vagas. Em relação ao grande número de pedidos para abertura de novos cursos de licenciatura, é importante destacar que ele ocorreu, sobretudo, em instituições privadas - os pedidos das universidades públicas eram relativamente poucos. O Censo do Ensino Superior, em 2001, trouxe, pela primeira vez, informações sobre os cursos de formação de professores a distância oferecidos no Brasil. Em 2000 foram disponibilizadas 6.430 vagas em cursos de graduação dessa natureza.

As universidades públicas brasileiras, por sua vez, destinam algo em torno de $20 \%$ de suas vagas a cursos de licenciatura. Apesar desse número significativo de vagas nas universidades públicas destinado à formação de professores e de, potencialmente, existir um contigente relativamente numeroso de novos profissionais do ensino diplomado a cada ano, não há perspectiva para que esse problema seja resolvido a curto prazo. Por que isso acontece?

De acordo com o Censo do Ensino Superior, no ano de 1997, cerca de 39.800 vagas deixaram de ser preenchidas em 13 diferentes cursos de licenciatura. Observou-se ainda um baixo número de formandos em relação às vagas oferecidas. Desistências, transferências para outros cursos, baixa procura em comparação aos cursos de bacharelado das demais áreas, esses considerados mais nobres, foram os principais problemas levantados para se explicar, pelo menos nas instituições públicas, o baixo número de formandos. E alguns desses cursos praticamente só existem nas universidades públicas, como, por exemplo, o de Física. Em 2001 existiam 112 cursos de licenciatura em Física em todo o Brasil, somente oito oferecidos nas particulares.

Os dados fornecidos pelo governo federal indicam que, ao mesmo tempo que existe a necessidade de formar/certificar um enorme número de professores e um crescimento na demanda para abrir novos cursos de licenciatura, há uma baixa ocupação de vagas nos cursos já existentes e um número relativamente baixo de graduandos em relação ao número de vagas oferecidas.

A dificuldade de os alunos manterem o seu sustento durante a graduação, ${ }^{4}$ a baixa expectativa de renda em relação à futura profissão e o declínio do status social da docência fizeram que os cursos de licenciatura, tanto em instituições públicas como privadas, convivessem com altíssimas taxas de evasão e, por via de consequência, permanecessem em constantes crises.

\section{Um modelo de formação profissional em crise}

Em meados da década de 1980, Donald Schön denunciou, nos Estados Unidos, a existência de uma profunda crise da formação profissional
${ }^{4}$ Levantamento socioeconômico feito com alunos que prestaram o "Provão" no ano de 2001 apontou que, em cursos de formação de professores, a maioria dos alunos vinha de família de baixa renda, cujos salários variavam de $\mathrm{R} \$ 541$ a $\mathrm{R} \$ 1.800$ (Cursos... 2001). 
norte-americana, devido, entre outros fatores, à predominância de um ultrapassado e ineficiente modelo de preparação de novos profissionais: o da "racionalidade técnica". Schön advogou, então, pela construção de uma "epistemologia alternativa da prática".

De acordo com o modelo da racionalidade técnica, também conhecido como a epistemologia positivista da prática, "a atividade profissional consiste na solução instrumental de um problema feita pela rigorosa aplicação de uma teoria científica ou uma técnica" (Schön, 1983, p. 21).

De acordo com Carr e Kemmis (1986), a visão de educação como uma ciência aplicada não é nova. Durante o século 19 e o início do século 20, muitas pessoas afirmaram que o ensino melhoraria pela aplicação do método científico. O papel da teoria seria iluminar o pensamento dos professores, isto é, "a teoria se relacionaria com a prática fornecendo o exame crítico das experiências educacionais práticas" (Carr, Kemmis, 1986, p. 56).

Conforme essa visão, a prática educacional é baseada na aplicação do conhecimento científico, e as questões educacionais são tratadas como problemas "técnicos" que podem ser resolvidos objetivamente por meio de procedimentos racionais da ciência. Além disso, "a teoria educacional pode usar leis causais para prever e, portanto, controlar os resultados de diferentes cursos da ação prática" (Carr, Kemmis, 1986, p. 66). Do mesmo modo, pesquisadores educacionais "puros" estão, como cientistas das Ciências Naturais, perseguindo conhecimento objetivo por meio de investigação científica, e pesquisadores da educação "aplicada" fornecem "respostas para questões científicas que foram levantadas dentro de um quadro de fins educacionais" (Carr, Kemmis, 1986, p. 70). Assim, ambos permanecem como atividades livres de valores e neutras.

Schön (1983, p. 26) discute, a partir do modelo hierárquico de conhecimento profissional, que a pesquisa é institucionalmente separada da prática. Em suas palavras,

\begin{abstract}
Pesquisadores supostamente fornecem a ciência básica e aplicada a partir da qual derivam técnicas para diagnóstico e solução dos problemas da prática. Profissionais supostamente suprem os pesquisadores com problemas para estudo e testes a respeito da utilidade dos resultados de pesquisa. O papel do pesquisador é distinto e normalmente considerado superior ao papel do profissional.
\end{abstract}

Do mesmo modo, Carr e Kemmis (1986, p. 70) afirmam que o papel do professor, baseado na visão científica da teoria e da prática educacional, é de passiva conformidade com as recomendações práticas dos teóricos e dos pesquisadores educacionais. Segundo eles,

Professores não são vistos como profissionalmente responsáveis por fazer decisões e julgamentos em educação, mas somente pela eficiência com a qual eles implementam as decisões feitas por teóricos educacionais; somente com base em seu conhecimento científico sobre a prática educacional, esta poderia ser melhorada. 
De acordo com Schön (1983, p. 28), a divisão hierárquica entre pesquisa e prática está também refletida no currículo da escola profissional. A regra é: primeiro, a ciência básica e aplicada, depois, as habilidades para a solução dos problemas advindos do mundo real. Assim, ele afirma:

\begin{abstract}
A partir do ponto de vista do modelo da racionalidade técnica institucionalizado no currículo profissional, o conhecimento real baseia-se em teorias e técnicas da ciência básica e aplicada. Portanto, essas disciplinas devem vir primeiro. "Habilidades" no uso da teoria e da técnica para resolver problemas concretos devem vir mais tarde, quando os estudantes já tiverem aprendido a ciência relevante primeiro, porque ele não pode aprender habilidades de aplicação sem antes aprender conhecimento aplicável e segundo porque habilidades são um tipo ambíguo e secundário de conhecimento.
\end{abstract}

Resumindo, de acordo com o modelo da racionalidade técnica, o professor é visto como um técnico, um especialista que rigorosamente põe em prática as regras científicas e/ou pedagógicas. Assim, para se preparar o profissional da educação, é necessário conteúdo científico e/ou pedagógico, o qual servirá de apoio para sua prática. Durante a prática, professores devem aplicar tais conhecimentos e habilidades científicos e/ou pedagógicos.

Há pelo menos três conhecidos modelos de formação de professores que estão baseados no modelo de racionalidade técnica: o modelo de treinamento de habilidades comportamentais, no qual o objetivo é treinar professores para desenvolverem habilidades específicas e observáveis (Avalos, 1991; Tatto, 1999); o modelo de transmissão, no qual conteúdo científico e/ou pedagógico é transmitido aos professores, geralmente ignorando as habilidades da prática de ensino (Avalos, 1991); e o modelo acadêmico tradicional, o qual assume que o conhecimento do conteúdo disciplinar e/ou científico é suficiente para o ensino e que aspectos práticos do ensino podem ser aprendidos em serviço (Zeichner, 1983; Liston, Zeichner, 1991; Tabachnick, Zeichner, 1991).

Dessa maneira, o rompimento com modelos de racionalidade técnica de formação profissional - e, por conseguinte, a superação da visão aplicacionista e do discurso prescritivo na formação de professores - representa também uma necessidade imprescindível para a superação da crise nos cursos de formação docente no País.

\title{
A crise da identidade profissional docente
}

Ser educador não se configura para a maior parte dos jovens hoje uma opção para a vida profissional. A bem da verdade, temos constatado que nem mesmo o próprio magistério, habilitação a que se destina seu curso superior, é, para muitos alunos dos cursos de licenciatura, uma alternativa sedutora ou um projeto de vida profissional. Até mesmo entre os que se candidatam a uma bolsa de "iniciação à docência" na 
${ }^{5}$ Por referências experienciais entendo tanto as práticas sociais construídas ao longo de toda a trajetória de vida - escolar ou não - dos sujeitos, antes, durante e depois de estes ingressarem em um processo formal de preparação de professores, como aquelas mais diretamente ligadas aos momentos específicos em que assumem a condição de docentes. Em relação às últimas, as experiências vivenciadas durante as etapas iniciais da carreira docente talvez tenham um impacto maior nesse processo de construção identitária por se tratar de um momento de grande indefinição e conflito para o educador em formação. Não conscientes disso, as instituições formadoras geralmente deixam a cargo dos próprios sujeitos a responsabilidade de assumirem as suas primeiras experiências docentes. A minha vivência enquanto formador tem demonstrado que, dependendo do que eles encontram pela frente, isso pode determinar inclusive sua permanência ou não na profissão. universidade - pleiteando uma primeira experiência na regência de classe - encontraremos estudantes que põem em dúvida a opção pelo magistério, devido fundamentalmente à desvalorização social, salarial e, digamos, acadêmica da profissão.

Assumir-se enquanto educador e optar conscientemente por um curso que o credencie para o exercício da profissão é um dos primeiros passos na direção da construção da identidade docente. Tal reconhecimento e escolha estão hoje comprometidos em função da representação social da profissão, fortemente marcada por um sentimento de inferioridade, mediocridade e incapacidade. As políticas públicas educacionais têm grande responsabilidade na construção e perpetuação desse significado, uma vez que a valorização do profissional da educação não consegue ir além de um discurso demagógico, que não se traduz em melhorias efetivas nas condições salariais e de trabalho dos professores.

O desprestígio acadêmico das atividades ligadas à educação nas instituições de ensino superior também contribui para que os jovens tenham dificuldade de se identificarem como alguém que está se preparando para o exercicio do magistério. Como sabemos, muitos cursos ainda privilegiam os bacharelados em detrimento das licenciaturas. Estas, concebidas na maioria das vezes apenas como apêndices dos primeiros, não têm, em muitos casos, identidade própria. Mesmo aqueles cursos que são reconhecidamente de licenciatura assumem feições de um curso de bacharelado, colocando em dúvida qual o tipo de profissional que ali se pretende formar. Soma-se a isso o fato de que muitos formadores nas universidades e nas instituições de ensino superior têm dificuldade de se enxergarem como professores ou formadores de professores, identificando-se apenas como pesquisadores. Estes sujeitos e suas representações do que sejam o ensino e a formação de professores também influenciam a maneira como os licenciandos reconhecem a si próprios (Diniz-Pereira, 1998). Consequentemente, é comum depararmos com estudantes nos momentos finais dos cursos de licenciatura em História, Geografia ou Biologia que se autodenominam historiadores, geógrafos ou biólogos em vez de professores das respectivas disciplinas. O fato de esses alunos não se reconhecerem como educadores ou "professores de", elemento fortemente influenciado pela significação social do magistério e provavelmente pelo status das atividades relacionadas às atividades de ensino no campo acadêmico, parece ser uma característica bastante significativa na construção de uma determinada identidade profissional - seja ela docente ou não.

Por outro lado, estudos (Diniz-Pereira, Fonseca, 2001) demonstram a influência positiva da participação em experiências educacionais diferenciadas - importantes para a construção daquilo que eu denomino "referências experienciais" 5 - ainda durante a formação acadêmicoprofissional para a construção de elementos de identidade docente. A maior parte dos licenciandos apontou a participação em tais experiências como decisiva em sua opção pela profissão de professor, em função de 
uma maior respeitabilidade que passam a conferir ao trabalho docente ao vivenciar a complexidade dos desafios do fazer pedagógico e da descoberta do prazer proporcionado pelas relações pessoais que a dinâmica de sala de aula oportuniza.

É nessa opção que começa a evidenciar-se o caráter contrastivo e relacional do conceito de identidade e mais especificamente da noção de identidade profissional docente, pois é a partir do momento que se assume a condição de educador - ou seja, quando a pessoa se coloca diante de outras e estas, reconhecendo-se como alunos, identificam-na como professor - que se inicia efetivamente o processo de construção da identidade docente. Mesmo que essa pessoa já tenha se imaginado nessa condição anteriormente, é só a partir da experiência concreta que esse processo será desencadeado. Tal constatação inevitavelmente nos faz pensar na inadequação dos cursos de formação inicial de professores do Brasil e de outros países, em que o estudante é capaz de concluir seu percurso na instituição formadora sem nunca ter assumido efetivamente o papel docente.

A especificidade dos alunos - se crianças, adolescentes ou adultos -, sua situação sociocultural e suas histórias de vida também parecem representar um aspecto importante na constituição dessa identidade profissional.

Este é um tema relativamente novo no campo da pesquisa sobre formação de professores no País; necessitamos, pois, de mais pesquisas para melhor compreender os impactos da crise da profissão docente na construção de uma determinada identidade profissional - seja ela docente ou não.

\section{Considerações finais}

Por fim, gostaria de ressaltar, ainda dentro da discussão sobre a crise da profissão docente no Brasil, que não podemos nos esquecer do princípio da indissociabilidade entre a formação e as condições adequadas para a realização do trabalho docente: salários dignos, autonomia profissional, dedicação exclusiva a uma única escola, pelo menos um terço da jornada de trabalho para planejamento, reflexão e sistematização da prática, estudos individuais e coletivos, salas de aula com um número reduzido de alunos. Do contrário, poderemos assumir, de um lado, uma posição de que tudo de ruim que existe na educação escolar acontece devido aos professores e sua "má formação" (tese da culpabilização) ou, de outro, a postura de que os docentes não têm nada a ver com os problemas atuais da escola, sendo, portanto, apenas vítimas de um sistema social e educacional perverso e excludente (tese da vitimização). Tais posições - a primeira, em geral, adotada pelas secretarias de educação e a segunda, pelos sindicatos dos professores - são pouco produtivas e pouco contribuem para o avanço desse debate. 


\section{Referências bibliográficas}

ARROYO, Miguel G. Quem de-forma o profissional do ensino? Revista de Educação AEC, Brasília, v. 14, n. 58, p. 7-15, out./dez. 1985.

AVALOS, B. Approaches to teacher education: initial teacher training. Londres: Commonwealth Secretariat, 1991.

BALZAN, Newton César. Ensino e pesquisa no ensino superior: uma relação mal resolvida? In: ENCONTRO NACIONAL DE DIDÁTICA E PRÁTICA DE ENSINO (Endipe), 7., 1994, Goiânia. Anais... Goiânia: UFG, UCG, 1994.

Hei de vencer, mesmo sendo professor ou a introjeção da ética do dominador. Revista de Educação AEC, Brasília, v. 14, n. 58, p. 16-21, out./dez. 1985.

BALZAN, Newton César; PAOLI, Niuvenius J. Licenciaturas: o discurso e a realidade. Ciência e Cultura, São Paulo, v. 40, n. 2, p. 147-151, 1988.

CANDAU, Vera Maria Ferrão. (Coord.). Novos rumos da licenciatura. Brasília: Inep, 1987.

CARR, W.; KEMMIS, S. Becoming critical: education, knowledge and action research. Londres: Falmer Press, 1986.

CURSOS de formação de professores têm alunos de menor renda. Folha de S. Paulo, 13 dez. 2001.

DINIZ-PEREIRA, Júlio Emílio. Formação de professores nas licenciaturas: um estudo de caso sobre o curso de Ciências Biológicas da UFMG. 1996. Dissertação (Mestrado em Educação) - Universidade Federal de Minas Gerais, Belo Horizonte, 1996.

O que professores de um curso de licenciatura pensam sobre ensino? Educação em Revista, n. 30, p. 107-113, 1998.

. Formação de professores: pesquisas, representações e poder Belo Horizonte: Autêntica, 2000.

DINIZ-PEREIRA, Júlio Emílio; FONSECA, Maria da Conceição Ferreira Reis. Identidade docente e formação de educadores de jovens e adultos. Educação e Realidade, Porto Alegre, v. 26, n. 2, p. 51-73, jul./dez. 2001.

EVANGELISTA, Olinda et al. Política educacional. Rio de Janeiro: D\&PA, 2000. 
HAGUETTE, André. Educação: bico, vocação ou profissão? Educação \& Sociedade, São Paulo, v. 12, n. 38, p. 109-121, abr. 1991.

HYPOLITO, Álvaro Moreira. Processo de trabalho na escola: algumas categorias para análise. Teoria \& Educação, Porto Alegre, n. 4, p. 3-21, 1991.

KREÜTZ, Lúcio. Magistério: vocação ou profissão? Educação em Revista, Belo Horizonte, n. 3, p. 12-16, jun. 1986.

LISTON, D.; ZEICHNER, K. M. Teacher education and the social conditions of schooling. Nova York: Routledge, 1991.

LÜDKE, Menga. Formação de docentes para o ensino fundamental e médio: as licenciaturas. Rio de Janeiro: Conselho de Reitores das Universidades Brasileiras (CRUB), 1994.

MARQUES, Carlos Alberto; DINIZ-PEREIRA, Júlio Emílio. Fóruns das licenciaturas em universidades brasileiras: construindo alternativas para a formação inicial de professores. Educação \& Sociedade. v. 23, n. 78, p. 117-142, abr. 2002.

PAGOTTO, Maria Dalva Silva. Formação e atuação: um estudo sobre representações de professores. 1988. Dissertação (Mestrado em Educação) - Universidade Federal de São Carlos (UFSCar), 1988.

SANTOS, Lucíola Licínio de Castro Paixão. Formação do(a) professor(a) e pedagogia crítica. In: FAZENDA, Ivani (Org.). A pesquisa em educação e as transformações do conhecimento. Campinas: Papirus, 1995. p. 17-27.

SCHÖN, D. The reflective practitioner. Nova York: Basic Books, 1983.

TABACHNICK, B. R.; ZEICHNER, K. M. (Org.). Issues and practices in inquiry: oriented teacher education. London: Falmer Press, 1991.

TANCREDI, Regina Maria Simões Puccinelli. A formação do professor nos cursos de licenciatura da área de ciências na UFSCar: uma análise da questão sob a ótica dos licenciandos. 1995. 470 p. Tese (Doutorado em Educação) - Universidade Federal de São Carlos (UFSCar), 1995.

TATTO, M. T. Conceptualizing and studying teacher education across world regions: an overview. [A background paper commissioned by the World Bank for the Conference Teachers in Latin America: New Perspectives on their Development and Performance - San Jose, Costa Rica]. 1999.

ZEICHNER, Kenneth. M. Alternative paradigms of teacher education. Journal of Teacher Education, n. 34, p. 3-9, May/June 1983. 
Júlio Emílio Diniz-Pereira, doutor em Educação pela University of Wisconsin, em Madison, nos Estados Unidos, é professor do Programa de Pós-Graduação da Faculdade de Educação da Universidade Federal de Minas Gerais (FaE/UFMG).

juliodiniz@ufmg.br

Recebido em 11 de novembro de 2010.

Aprovado em 22 de dezembro de 2010. 